\title{
A FRAMEWORK FOR INTERPRETING KNOWLEDGE, ATTITUDE AND PRACTICES STUDY IN POISONING INCIDENTS OF HOUSEHOLD CHEMICAL PRODUCTS
}

\author{
INDAHAYU AB RAHMAN ${ }^{1}$, MOHAMAD SHAHARUDIN SAMSURIJAN ${ }^{2}$, NUR AZZALIA \\ KAMARUZAMAN $^{1}$, NORHANIZA AMIL ${ }^{3}$ AND MOHD HAFIIDZ JAAFAR* $* 1,3$ \\ ${ }^{1}$ National Poison Centre, ${ }^{2}$ School of Social Sciences, Universiti Sains Malaysia, 11800 Pulau Pinang, Malaysia. ${ }^{3}$ School of \\ School of Industrial Technology, Building G07, Persiaran Sains, Universiti Sains Malaysia 11800 Pulau Pinang, Malaysia.
}

*Corresponding author: mhafidz@usm.my

Submitted final draft: 8 August $2020 \quad$ Accepted: 9 August 2020

http://doi.org/10.46754/jssm.2021.06.019

\begin{abstract}
Poisoning by accidental or intentional ingestion, injection or inhalation of household chemical poisons are the most common cases reported and received by the Malaysia National Poison Centre. In Malaysia, a notable increase of approximately $94 \%$ of incidents occurred at home through the ingestion route. Most poisoning incidents can be extrapolated from the demographic factors of a community. The objective of this study is to construct a conceptual framework of knowledge, attitude, and practices (KAP) for household chemical product poisoning. This manuscript is being prepared with the focus of improving community health and well-being, as suggested in Goal 3 of Sustainable Development Goals. In the initial stage of constructing this framework, the data sources were gathered from the National Poison Centre (primary data source), and a comprehensive electronic-based search was conducted on the frequent and common keywords to identify scientific reports related to this study topic. The framework of the developed KAP contains four main sections, which are demographic variables, knowledge, attitude, and practices. At the end of the study, the level of awareness of the household chemical product poisoning can be measured based on the defined context of the KAPs framework.
\end{abstract}

Keywords: Household chemical, poisoning, knowledge, attitude, practice.

Abbreviations:

KAPs (Knowledge, attitudes and practices study)

WHO (World Health Organisation)

\section{Introduction}

According to the World Health Organisation (WHO) (2000), poisoning incidents have become a significant problem worldwide, particularly in developing countries. In 2020, the Global Burden of Disease Study stated that almost 42,848 poisoning cases worldwide were reported to the authorities (Barratt, 2020). However, not all cases of poisoning were reported to poison centres, and the number of incidences may possibly be higher as most cases of poisonings actually go unreported. Therefore, poisoning data fell short of representing the actual occurrence of poisoning in each country (Bundotich \& Gichuhi, 2015; G/Mariam \& Gelaw, 2016). This poisoning problem is also getting worse with time as the growth and development of newer drugs and chemicals are gradually increasing.
Household chemical products poisoning by accidental ingestion, injection or inhalation is the most commonly reported cases in medical emergency departments (Kassiri et al., 2012; Adnan et al., 2013; Tangiisuran et al., 2017). Household chemical products, such as cleaning products and toiletries, are commonly used items and can be easily found in all homes all over the world. The products, such as bleach, cleaners, disinfectants, and detergents, have become essential products to maintain the cleanliness and hygiene of daily human life. Since the chemical contents in these kinds of products are often harmful and poisonous, they can pose serious risks to people's health and environment. Nearly all of the household solution contains approximately $22 \%$ of harmful chemicals, such as formaldehyde and sodium chloride (EWG's Guide to Healthy Cleaning, n.d) which could 
promote a range of adverse side effects, such as nausea, burning sensation, coughs, and sore throat. Therefore, these household chemical products must be used according to their instructions to ensure the safety of its users and their surroundings.

Unfortunately, these household cleaning products have become one of the most common reagents that caused an increase in poisoning incidents globally, whether unintentionally or intentionally. Adinew et al. (2017) reported that between $25 \%$ and $35 \%$ of 543 poisoning cases during their study period were patients poisoned with bleaching reagents. Meanwhile, Mckenzie et al. (2010) stated that household cleaning products were responsible for many unintentional poisoning cases among children and consistently remained among the top causative agents for paediatric poisoning exposure. The causes of this household chemical product poisoning are multi-factorial, and must be analysed further to understand and strategise for better prevention methods.

Poisoning incidents caused by household chemical products occur due to the exceeded level of toxicity and the duration of exposure to the products (Cleveland Clinic, 2018). Household chemical products poisonings are categorised as either unintentional or intentional. Unintentional poisoning is defined as the exposure by any route where there is no intention to cause harm (Tangiisuran et al., 2018), and children are prone to this kind of poisoning. Death from unintentional poisoning commonly occurs in low- and middle-income groups (Gorea, 2009; Adnan et al., 2013; Tangiisuran et al., 2017). According to data from the WHO (2012), an estimated 193,460 people died worldwide from unintentional poisoning in 2012. These incidents had lowered the quality of life globally in the aspect of health. Carelessness in handling household chemical products and lack of concern by family members in regards to the urgency of this issue is the most common factors that contribute to many unintentional cases of poisoning (Dayasiri et al., 2018; Peshin \& Gupta 2018).
Intentional poisoning can be classified as suicidal cases and involves the fatalities of nearly a million people each year (WHO, 2019). This poisoning incident category can be defined as exposure by any route where there is an intention to cause harm (Tangiisuran et al., 2018). The WHO (2008) estimates that deliberate ingestion of household chemical poisons causes 370,000 fatalities per year. Moreover, from the 23 million poisoning cases annually, about 2 million was estimated as intentional poisonings that resulted in about 200,000 suicides (Moazzam et al., 2009; Banerjee et al., 2012; G/ Mariam \& Gelaw, 2016). The high occurrence rates may be attributed to ethnicity, cultural and geographical factors (Azizpour et al., 2016). Generally, most intentional poisoning cases originate from people in the age group of 15-19 years old (Adnan et al., 2013). Most previous studies reported that males were significantly involved in intentional poisoning, based on the high number of poisoning exposure calls recorded (Jesslin et al., 2010; Rajapakse et al., 2014).

In a developing country like Malaysia, approximately $96 \%$ of poisoning exposure cases (household products, pharmaceutical products, and pesticides were the common agents) were reported to occur at home (Tangiisuran et al., 2017). The unintentional and intentional poisoning cases from the National Poison Centre (NPC) database as referred to in Figure 1 can be further analysed with extrapolation of demographic factors of the human population to prevent or lower the incidents of poisoning (Marks \& Hoving, 2016). In this paper, a framework was constructed to identify the epidemiology of poisoning, as well as geographical and individual factors (knowledge, attitude, and practices) in a defined population.

According to the NPC, more than 50,000 poisoning cases were referred for inquiries from 1995 to 2017 (Figure 1), while 53\% of the poisoning incidents from 2006 to 2016 were caused by household chemical products (Figure 2). Since then, this centre has observed an annual increase in the number of poisoning cases referred. 


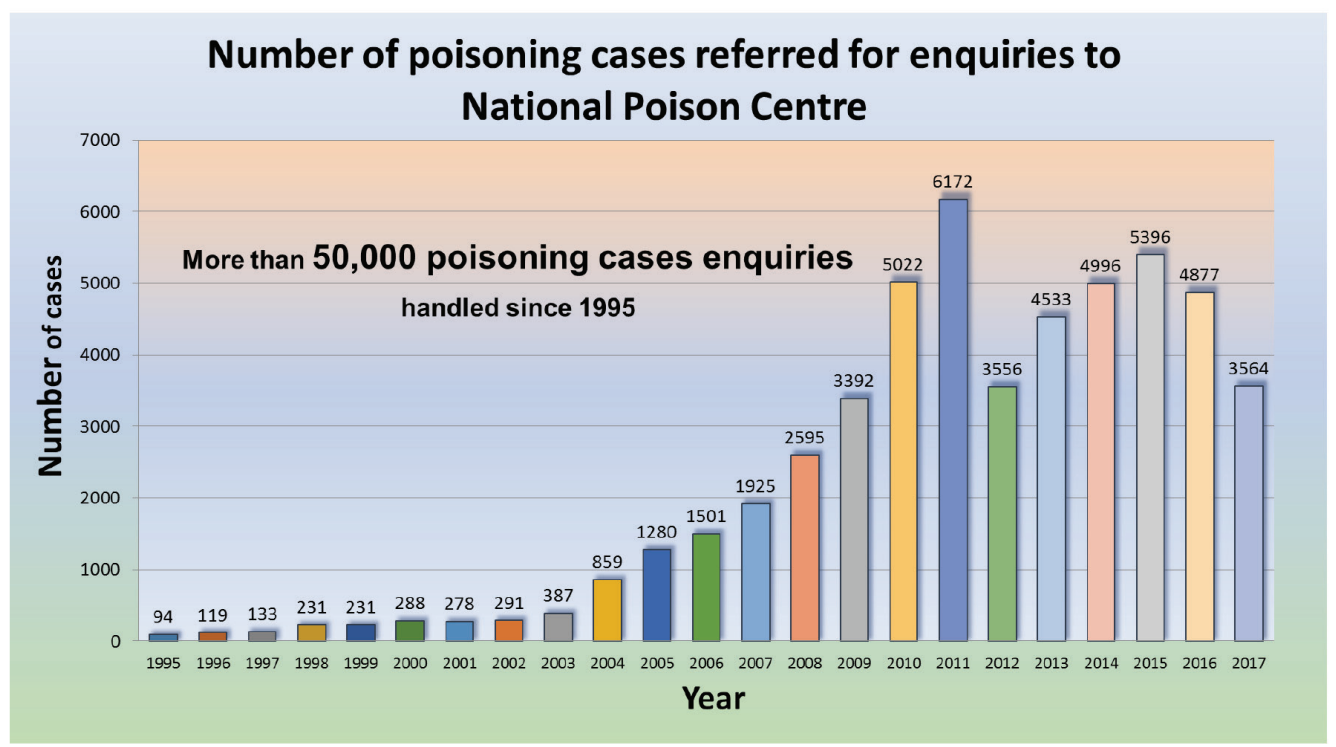

Figure 1: The number of poisoning cases reported to the National Poison Centre (NPC) from 1995 until 2017. (Source: National Poison Centre)

\section{Number of household product poisoning cases referred to NPC for enquiries in 2006-2016}

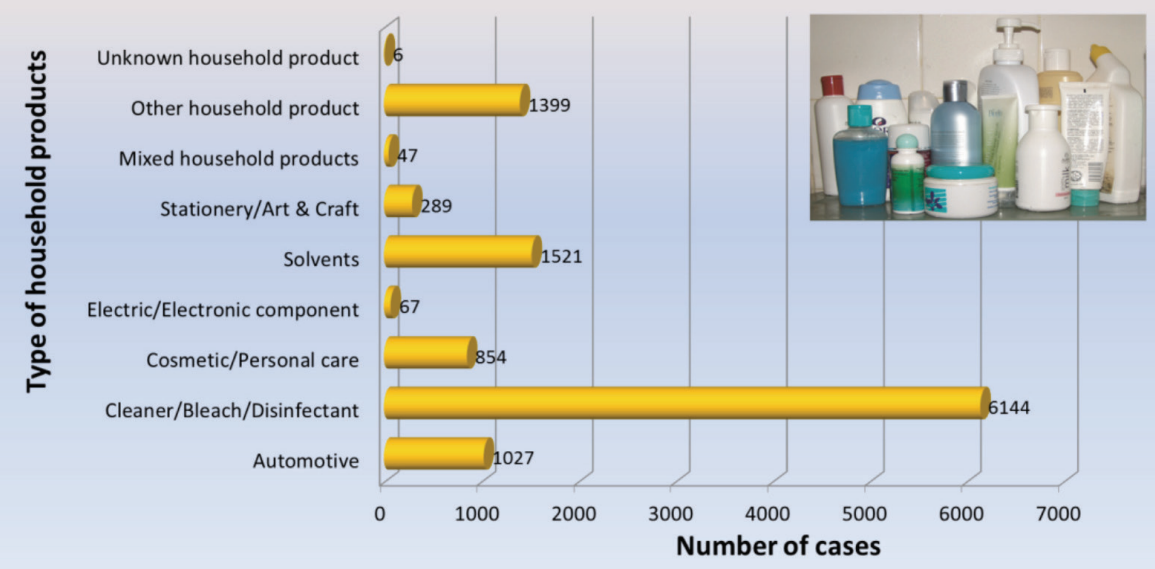

Figure 2: The number of poisoning cases reported to the National Poison Centre from 2006-2016, grouped by the type of poisoning reagent. (Source: National Poison Center)

\section{Methodology}

In constructing the framework of the knowledge, attitude, and practice study (KAP study) on household chemical poisoning, the NPC database became the primary data source, and retrospective reviews of the database was conducted from 1995 to 2017 . This centre also had noted an annual increase in the number of poisoning cases referred. In addition, household cleaning products were recorded as the highest household chemical reagent that caused poisoning incidents, followed by solvents 
(thinner and turpentine) and other household products.

Following the initial study on the NPC database, a comprehensive electronic-based search was performed on the frequent and common keywords to identify scientific reports related to this study topic. Selected publications from the past 12 years were reviewed. Other relevant review articles and older publications were also studied, and there were no language restrictions in any publication. The search terms included the words "household chemical products", "children", "poisoning", "unintentional and intentional", "KAP study in poisoning", and the most common one is "household cleaning products". All the journals referred to in this study were ranked using the Scimago Journal and Country Rank. Thus, journals with ranking Q1- Q4 were reviewed in this study.

\section{Results and Discussion}

\section{The KAP framework for household chemical products poisoning}

Figure 3 depicts the conceptual framework of the KAP from all inputs and information gathered during data searching and sourcing. The framework aims to identify the indicators that can help researchers perform any improvement of development and implementation of poisoning awareness. The developed KAP framework contains four main sections, which are demographic variables, knowledge, attitude, and practices. Demographic variables and the KAPs can be indicators for the risk of poisoning (Presgrave et al., 2008). The variable patterns of poisoning cases mostly depend on the demographic variables of the individual itself (Peshin \& Gupta, 2018). In Egypt, many children in rural areas are affected by home injuries, especially poisoning, and the associated factors of these incidents are their parents' knowledge, attitude, and practices (Eldosoky, 2012).

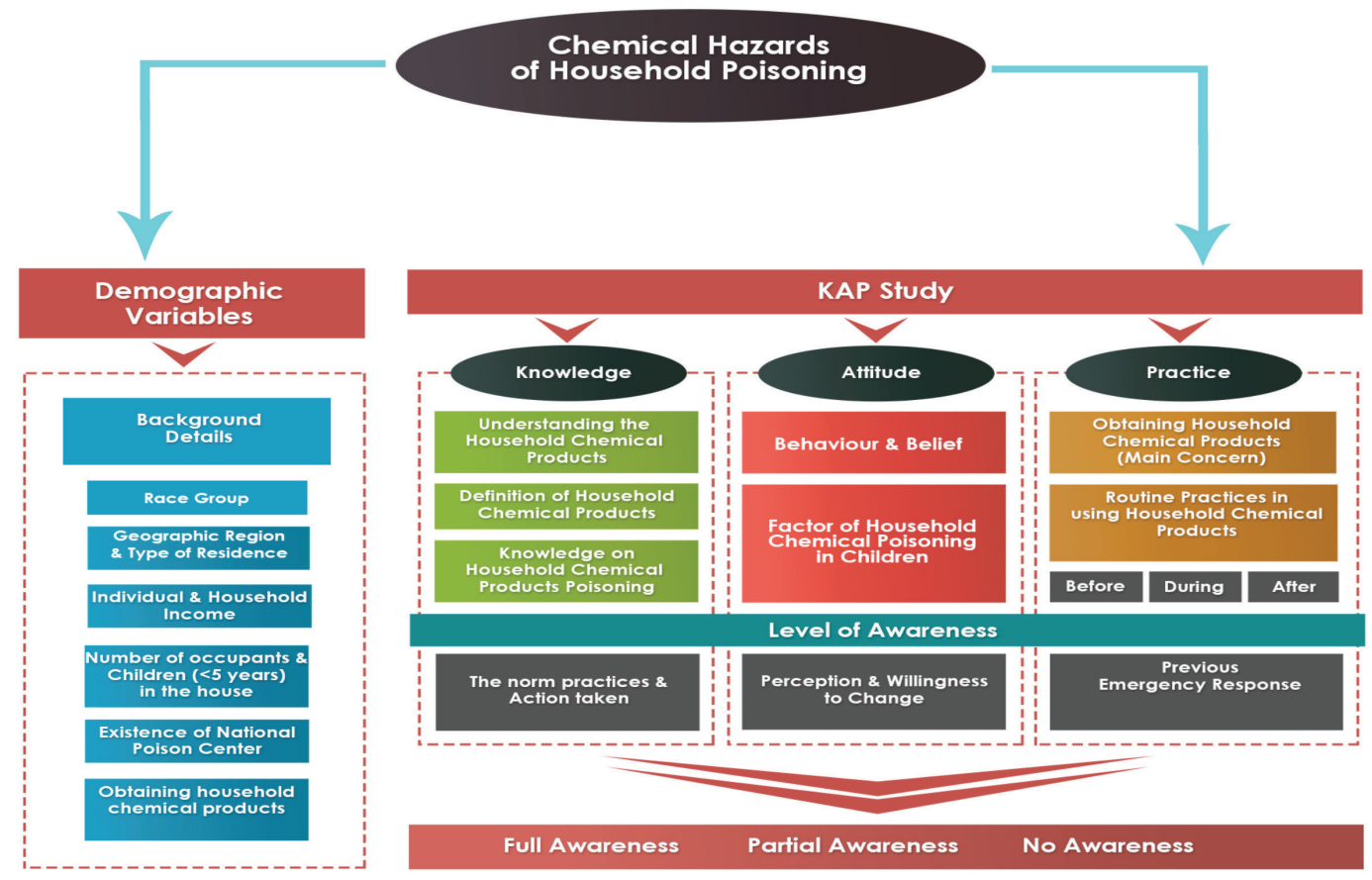

Figure 3: Conceptual framework of knowledge, attitude, and practice (KAP) on household chemical products poisoning 
At the end of the framework, the level of awareness was measured through the KAPs contexts. The final results divided the population into three groups, which are full awareness, partial awareness, and no awareness. Each context has its indicators or inputs to evaluate the particular population. Awareness of household chemical products poisoning issues among the population has not been well described. Thus, this study could reinforce it by addressing the actual local relevance problems.

\section{Demographic Variables}

Demographic variables are an essential component of this KAPs framework (Figure 3, part: demographic variables) as these epidemiology data provide information by the respondents that may help this study indicate the factors influencing household chemical poisoning (Manzar et al., 2010; World Health Organisation (WHO), 2010; Jarrah et al., 2018; Sena et al., 2018). Moreover, previous research has proven that a variety of social and demographic variables (such as geographic location, age of respondents, gender, education background, household size, residential characteristics, ethnic group, income and marital status) influenced unintentional poisoning cases (Centers for Disease Control and Prevention (CDC), 2006; Franklin \& Rodgers, 2008; Gheshlaghi et al., 2013).

From the data sources collected, the epidemiology data of an individual in a defined population that are correlated with the study topic are included in the framework. The background details in Figure 3, which are needed in this study like, gender (male or female), age, education level, and marital status. Some studies had proven that these details need to be taken into consideration as these variables could influence the occurrence of poisonings (Manzar et al., 2010). For example, it was found that most individuals with a higher education level were classified as prone to having children being involved in household poisonings (Manzar et al., 2010). This is because the children were being neglected as a result of busy and workaholic parents who strived for career advancement
(Manzar et al., 2010). The average household size in Malaysia is 4.1 in the year 2016 (Department of Statistic Malaysia, 2017). Most Malaysian households has at least four members, which can be classified as the core family members. Sackitey (2018) found that the frequency of home accidents was lower among children who live in a core or nuclear family compared with those living in an extended family. In addition, Kielb et al. (2015) stated that indoor air quality could be affected if the number of occupants in the house was overloaded.

Manzar et al. (2010) had suggested for future study that a large scale of variables, like ethnicity and geographic differences, for household poisonings were needed as they believed that these factors could have an impact on different cultures and practices. Lam (2003) had suggested that people in rural areas could have a higher chance of poisoning exposure due to agricultural activities. Poisoning incident factors may vary according to regions, society's (ethnic) traditions and customs, levels of education, and seasons (Sivri \& Ozpulat, 2015). They also reported that people with functional economic status would have a higher level of knowledge and awareness about household chemical poisonings (Sivri \& Ozpulat, 2015). Therefore, this study had included the variable for household income based on the group classification as defined by the Department of Statistics Malaysia (DSM, 2017). There are four groups of household income, which are poverty (measured by Poverty Line Income, PLI), B40 ( $\geq$ RM2848), M40 ( $\geq$ RM 6502), and T20 ( $\geq$ RM16088). Besides, this study will consider the number of children in the house aged between 0 and 5 years old as most of the reported poisoning cases involved this age group (Rosenberg et al., 2011; Akturk \& Erci, 2016; Peshin \& Gupta, 2018). Children below the age of 5 years old are a major concern of this study as they are particularly active and have an exploratory nature with a strong impulse to put things into their mouths. Moreover, living with parents who are likely to be inattentive and neglectful exacerbated the children's vulnerable situation (Hunt, 2013). 


\section{Knowledge}

In KAP surveys, knowledge is one of the main aspects that will define the extent of community awareness of public health concept. Every person has a different level of knowledge towards chemical hazards of household poisonings. Availability of such information could bring benefit to poison management control centres in planning preventive interventions to educate the community efficiently. A study by Goktas et al. (2014) evaluated respondents' knowledge on the information regarding poisoning cases involving the household chemical products. It was mentioned that respondents' knowledge is affected by their health education background and level of awareness. The WHO (2005) believed that high-level knowledge is one of the preventive measures and the most significant component that influences the responses in poisoning cases. It is crucial because poisonings due to household chemical products can lead to mortality and morbidity in humans.

The context of knowledge in this study is to assess the extent to which individuals from a household are aware of public health concepts regarding household chemical products usage (as shown in Figure 3, part: knowledge). Focus group questions further contextualised the targeted community poisoning knowledge and understanding of household chemical product management. A study had shown that the majority of people, in their study sample, had minimal knowledge of prevention strategies and revealed misinformation about poisoning (Bogar et al., 2017). This study will not be limited to knowledge of biochemical facts, but the general understanding that could measure the level of awareness and the public's literacy, such as the type of household chemical products and poisoning risk assessments. Questions on respondents' understanding were developed in this study, such as "can they differentiate well the hazardous household chemical products in their house?" and "are they aware and do they know the factors that may lead to poisoning?"

Education backgrounds and understanding of household chemical poisonings (potential risks of accidental poisoning from a home environment) of guardians (parents, grandparents and caregivers) or those entrusted with the care of children and other individuals are essential in responding to poisoning incidents (Peshin \& Gupta, 2018). Thus, this study included education backgrounds as a variable because the data could influence the level of knowledge of the risks of household chemical poisonings. According to the National Safety Council (2019), the public should acknowledge and make an informed decision about the type of household products they buy and bring into their homes. They also need to understand very well the terms and definition found on the products to avoid any poisoning incidents. Parents' knowledge on poisonings is essential in injury care for children as many adverse consequences of the incidents can be averted if parents know how to respond to them (Ibrahim, 1991; Eldosoky, 2012).

Having an understanding of household chemical products will reduce the possibility of poisoning occurrences in selected populations. This study identified the main risk factors for unintentional and intentional poisoning in the investigated population. A further focus was given to finding the possible causes of household chemical poisoning. Many studies were conducted on the causes of poisoning in different parts of the world. Most of the poisoning factors occurred because of ingestion of household chemicals (Mansori et al., 2016). The trend of multiplying poisoning cases follows the introduction of new and various household chemical products, the increasing number of new consumer products and greater accessibility and exposure of children to these products (Balai-Mood, 2004; Mansori et al., 2016).

In this context of knowledge, the measurement to identify the level of awareness also considered the norm practices and responses to poisoning incidents. Most people live with dangerous poisons in their household. This living norm increases the risks of poisoning if it is not well managed (Rosenberg et al., 2011; National Safety Council, 2019). Referring to 
Figure 3, the last part of knowledge, familiarity versus awareness means that many people have normal practices in their life based on familiarity, without any concern of awareness. Some people cannot recognise that their normal practices could bring physical and health hazards to their household. Most parents and caregivers practised bad habits of household chemical product management and, therefore, risked their children's life. An example of a bad norm is keeping hazardous household chemical products in the wrong places or unlatched storages in the house (Gutierrez et al., 2011).

\section{Attitude}

Attitude is difficult to define, and even within the expert psychological realm, there is little agreement as to what is understood by it (Mbeng et al., 2009). With that statement, the context of attitude in this study was focused on determining beliefs, behaviours, and attitudinal factors of household chemical poisonings. Attitude means a complex mental state involving beliefs, feelings, values, which facilitates a predilection to behave or act in a particular way (Sharif \& AlMaliki, 2010; Akabanda et al. 2017). Moreover, attitude may attribute to the characterisation of an individual's feelings and inclinations, with regards to household chemical product usages (Muleme et al., 2017). The characterisation can be defined as negative (bad) or positive (good) in relation to the scientifically documented risks of household chemical products poisonings. The translation of correct knowledge into practices can be utilised for the reduction of poisoning cases through a change of belief (attitude) concerning household chemical hazards (Sharif \& Al-Malki, 2010). Figure 3 (Attitude part) illustrates the context of attitude in this framework.

Behaviour and belief are related to an individual's attitude. In one study, one part of the cross-sectional study rated people's beliefs on the poisonous level of household chemical products (Rosenberg et al., 2011) and from that, the attitudinal scale could be measured. The rate of beliefs on household items of hazardous level could show how much people recognise and are concerned about the potential of household chemical products causing harm and severe poisoning to their family, especially children. It was believed that household or laundry cleaning products were the products that lead to poisoning incidents (Presgrave et al., 2008; Rosenberg et al., 2011; Tangiisuran et al., 2018).

Every year, more than one million children below the age of 5 experience potentially toxic ingestions (Watson et al., 2004; Lai et al., 2006; Franklin \& Rodgers, 2008). Poisoning may occur in common locations, like homes, often in the living/dining room, kitchen, or bedroom as these are the locations where children (potential victims) spend most of their time (Bertinelli et al., 2006; McKenzie et al., 2010). Children in this age range are the most vulnerable group to be exposed to household chemical poisoning (Awang et al., 2003; Lam, 2003; Gutierrez et al., 2011; Tangiisuran et al., 2018). They have a high prevalence of acute poisoning as they are likely to taste or swallow harmful substances (Haghighat \& Moatamedi, 2012; Adnan et al., 2013) due to their behaviour; curious, exploratory in nature, and prone to putting things in their mouths (typical of early childhood development) (Lekei et al., 2017; Peshin \& Gupta, 2018). Therefore, strict supervision by adults is mandatory, and the reflection of attitude and perception (belief) of parents may affect preventive action (Rosenberg et al., 2011). Moreover, parents must teach the right attitude towards effective and safe management, and practices of household chemical products at home.

In the attitude context, the level of awareness could be measured from the population's perceptions and willingness to change. A study by Rosenberg et al. (2011) indicated that the majority of their respondents did not intend to change themselves to reduce the risk of poisoning. It was also reported that individuals who had completed university education might have more awareness and motivation to prevent the occurrence of poisoning (Eldosoky, 2012). Therefore, it is important to perform epidemiology surveillance 
to assess the magnitude of poisoning issues and identify significant risk factors to instil a positive attitude with the right beliefs and perceptions among the people (Presgrave et al., 2008). To ensure an effective reduction of poisoning risks, initiating changes to the fixed environment must be supported by enforcement of regulations, adequate education for industries and the community, with clear labelling on the products (Nixon et al., 2004). In short, an individual's attitude can be affected by their surroundings, such as the presence of economic, marital, or sibling-related problems, and family social support (Dayasiri et al., 2017).

\section{Practices}

Practices in this study can be referred to in Figure 3 (Practice part), which indicates any action related to household chemical products, right from purchasing to usage, to management and storage. In short, practices can be defined as the real action in performance based on knowledge and attitude (Agbedia, 2013). The right and suitable knowledge gained from dependable sources could change people's attitude and lead to proper practices that decrease the risk of poisoning cases (Sharif \& Al-Malki, 2010). Ideally, most people are more agreeable to practise the right procedures that have scientific or evidence-based information (Brownson et al., 2009). In developing proper practices that may overcome poisoning cases, household chemical products management needs to be implemented appropriately (Lekei et al., 2017).

There are varieties of household chemical products in the market. One of the studies indicated that any action related to household chemical products, right from purchasing to usage, to management and storage. It is expected that most people prefer products with the highest quality (Muleme et al., 2018). Moreover, the places where the study population buy their products play a significant role in their purchase decision. Based on the previous study, people were more likely to go to supermarkets or hypermarkets to purchase cleansing products (Maciejewski, 2016) as these large-scale retailers sell various brands and types of basic household and cleaning products (Hassan et al., 2013).

Many people show poor knowledge on home poisoning and lack proper practices in the usage of household chemical products, which led to poor practices of poisoning prevention strategies (Gutierrez et al., 2011). As a result, vulnerable and innocent children became the ultimate victims. A study suggested that poisoning prevention strategies should be about creating awareness, as well as listing the essential dos and don'ts for household chemical usages (Peshin \& Gupta, 2018). The strategies should also be evident in dictating safe routine practices before, during, and after the usage of household chemical products. Significant contributing factors need to be addressed through prevention programmes and measures to reduce the risks of poisoning. Common practices, like improper storage and careless handling of household chemical products, pose a higher risk of poisoning incidents at home (Gorea, 2009). For example, some people have a habit of storing their household cleaning products under their kitchen sinks or on the floor in their backyards, which are within the reach of children.

As observed in Figure 3, for the practice part, a census was created to measure the targeted population's experience of household chemical poisoning in a particular community. Data from this census can be analysed to conclude the actions taken when poisoning occurs (Rosenberg et al., 2011). For example, the appropriate use of the immediate first aid is vital during a poisoning emergency as this action could save a person's life or lower the severity of poisoning. This particular action could be evaluated in this study to determine a respondent's action to the response of poisoning incidents at home. On another note, it has been reported that $41 \%$ of callers from Puerto Rico in 2008 who sought advice regarding home poisoning incidents had completed first-aid courses and had filled in reports to their respective Poison Information Centers (Gutierrez et al., 2011). This further highlights the importance of home poisoning 
prevention knowledge and the role of poison control centres as effective strategies to guide people to respond to emergency home poisoning incidents with suitable and efficient practices that could save human lives.

\section{Conclusions}

Household chemical products are considered vital in our daily lives, and products of various types can be found in almost all homes. However, easy accessibility and careless storage, coupled with trivial parental supervision are becoming core causes of accidental children poisoning incidents. The differences observed in the poisoning reagents responsible for both accidental and intentional poisoning incidents in different countries and different communities depend on social status and prevalent cultural practices. As noted above, knowledge alone may not be adequate in preventing poisoning as positive attitudes and correct practices are also needed for more effective interventions. Children are particularly affected when it comes to poisoning due to differences in the aspects of physiology, behaviour, and biological defences, thus making them vulnerable to unintentional poisoning by ingestion. Hence, poisoning incidents can only be reduced by broad-based preventive strategies, including enforcement of safe manufacturing practices (like childlocked caps) and public education programmes (through campaigns and media). Furthermore, poison prevention measures must essentially shift from self-education of adults to advocating the correct knowledge, attitude and practices to the children.

\section{Acknowledgments}

This research study was supported financially by the Penang Government and MRUN the Translational Research Grant with the reference number of PRO-S-1012-I060 and 304. PTEKIND.656207, respectively. The author would like to extend the gratitude to colleagues who provided insight and expertise that majorly assisted the research study.

\section{References}

Adinew, G. M., Woredekal, A. T., DeVos, E. L., Birru, E. M., \& Abdulwahib, M. B. (2017). Poisoning cases and their management in Emergency Centres of Government Hospitals in Northwest Ethiopia. African Journal of Emergency Medicine,7(2), 7478. doi:10.1016/j.afjem.2017.04.005

Adnan, L. M., Kamaldin, J., Mohamad, N., Salatore, S. A., Suhaimi, R., Zainuddin, N., \& Mohamad Shariff, M. H. (2013). The risk of accidental chemical poisoning cases among children ( $\leq 12$ years old) admitted to Hospital University Sains Malaysia: 5 years review. Journal of Clinical Toxicology, 3(5), 3-7. doi:10.4172/2161-0495.1000177

Agbedia, C. (2013). Knowledge, attitude and practice (KAP) of sandwich under graduate students of Delta State University, Abraka, Nigeriaon condom use in the prevention of sexually transmitted infections (STls) and unwanted pregnancy. IOSR Journal of Humanities and Social Science, 7(4), 7378. doi: 10.9790/0837-0747378

Akabanda, F., Hlortsi, E. H., \& OwusuKwarteng, J. (2017). Food safety knowledge, attitudes and practices of institutional food-handlers in Ghana. BMC Public Health, 17(1). doi:10.1186/s12889016-3986-9

Akturk, U., \& Erci, B. (2016). Determination of knowledge, attitudes and behaviors regarding factors causing home accidents and prevention in mothers with a child aged 0-5 years. Journal of Education and Practice,7(18), 142-153. doi:10.1002/14651858.CD009882.pub2

Awang, R., Abd Rahman, A. F., A Wan Abdullah, W. Z., Lajis, R., \& Abdul Majid, M. I. (2003). Trends in inquiries on poisoning: A five-year report from the National Poison Centre, Malaysia. Medical Journal of Malaysia,58(3), 375-379.Azizpour, Y., Asadollahi, K., Savehmiri, K., Kaikhavani, S., \& Abangah, G. (2016). Epidemiological survey of intentional poisoning suicide 
during 1993-2013 in Ilam Province, Iran. BMC Public Health, 16(902), 1-12. doi: 10.1186/s12889-016-3585-9

Balai-Mood, M. (2004). Pattern of acute poisonings in Mashhad, Iran 1993-2000. Clinical Toxicology, 42(7), 965-75.

Banerjee, I., Tripathi, S. K., \& Roy A. S. (2012). Clinico-epidemiological characteristics of patients presenting with organophosphorus poisoning. North American Journal of Medical Sciences, 4(3), 147-150.

Barratt, I. (2020). Global deaths due to various causes and COVID-19. Bertinelli, A., Hamill, J., Mahadevan, M., \& Miles, F. (2006). Serious injuries from dishwasher powder ingestions in small children. Journal of Paediatrics and Child Health, 42(3), 129-133. doi:doi:10.1111/ j.1440-1754.2006.00811.x

Bilgen Sivri, B., \& Ozpulat, F. (2015). Mothers' knowledge levels related to poisoning. Turkish Journal of Emergency Medicine, 15(1), 13-22. doi:10.5505/1304. 7361.2014.25582

Bogar, S., Szabo, A., Woodruff, S., \& Johnson, S. (2017). Urban youth knowledge and attitudes regarding lead poisoning. Journal of Community Health, 42, 1255-1266. doi: 10.1007/s10900-017-0378-8

Brownson, R. C., Chriqui, J. F., \& Stamatakis, K. A. (2009). Understanding evidencebased Public Health Policy. American Journal of Public Health, 99(9), 15761583.doi:10.2105/ajph.2008.156224

Bundotich, J. K., \& Gichuhi, M. M. (2015). Acute poisoning in the Rift Valley Provincial General Hospital, Nakuru, Kenya: January to June 2012 JK. South African Family Practice, 57(3), 214-218. doi:10.1080/207 86190.2014.975448

Centers for Disease Control and Prevention (CDC). (2006). Nonfatal, unintentional medication exposures among young children: United States, 2001-2003. MMWR Morb Mortal Wkly Rep, 55(1), 1-5.
Cleveland Clinic. (2018, May 24). Household chemical products and their health risk. Retrieved December 6, 2018, from https://my.clevelandclinic.org/health/ articles/11397-household-chemicalproducts-and-their-health-risk

Dayasiri, M. B. K. C., Jayamanne, S. F., \& Jayasinghe, C. Y. (2018). Patterns and outcome of acute poisoning among children in rural Sri Lanka. BMC Pediatrics, 18(274), 1-8. doi: 10.1186/s12887-018-1246-0

EWG's Guide to Healthy Cleaning. (n.d.). Household cleaner ratings and ingredients. Eldosoky, R. S. H. (2012). Home-related injuries among children: Knowledge, attitudes and practice about first aid among rural mothers. Eastern Mediterranean Health Journal,18(10), 1021-1027. doi:10.26719/2012.18.10.1021

Franklin, R. L., \& Rodgers, G. B. (2008). Unintentional child poisonings treated in United States Hospital Emergency Departments: National estimates of incident cases, population-based poisoning rates and product involvement. Pediatrics, 122(6), 1244-1251. doi:10.1542/peds.2007-3551

G/Mariam, E. T., \& Gelaw, B. K. (2016). Global epidemiology of acute poisoning with an emphasis to Ethiopia: Systematic review. IInternational Journal of Pharma Sciences and Scientific Research, 2(4), 120-130. doi:10.25141/2471-6782-2016-4.0161

Gheshlaghi, F., Piri-Ardakani, M., Yaraghi, M., Shafiei, F., \& Behjati, M. (2013). Acute poisoning in children; A population study in Isfahan, Iran, 2008-2010. Iranian Journal of Pediatrics, 23(2), 189-193.

Goktas, S., Yildirim, G., Kose, S., Yildirim, S., Ozhan, F., \& Senturan, L. (2014). First aid knowledge of university students in poisoning cases. Turkish Journal of Emergency Medicine,14(4), 153-159. doi:1 $0.5505 / 1304.7361 .2014 .15428$

Gorea, R. (2009). Prevention and current scenario of unintentional poisoning. Journal 
of Punjab Academy of Forensic Medicine \& Toxicology, 9, 54-57.

Gutierrez, J., Negrón, J., \& García-Fragoso, L. (2011). Parental practices for prevention of home poisoning in children 1-6 years of age. Journal of Community Health, 36(5), 845-848.doi:10.1007/s10900-011-9384-4

Hasliza, H., Sade, A. B., \& Rahman, M. S. (2013). Malaysian hypermarket retailing development and expansion. International Journal of Retail and Distribution Management, 41(8), 584-595. doi: 10.1108/ IJRDM-09-2012-0085

Hunt, J. C. (2013). Associations between different parenting styles and child behavior (Doctoral dissertation, Philadelphia College of Osteopathic Medicine) (pp. 1-66). Pennsylvania: PCOM Psychology Dissertations.

Ibrahim A. (1991). Assessment of knowledge, attitude and practice of mothers attending Cairo University Hospital toward home accidents among preschool children (MSc thesis). Cairo, Egypt, Higher Institute of Nursing, University of Cairo.

Jarrah, S., Judeh, M., \& AbuRuz, M. E. (2018). Evaluation of public awareness, knowledge and attitudes towards basic life support: A cross-sectional study. BMC Emergency Medicine, 18(37), 1-7. doi: 10.1186/ s12873-018-0190-5

Jesslin, J., Adepu, R., \& Churi, S. (2010). Assessment of prevalence and mortality incidences due to poisoning in a South Indian Tertiary Care Teaching Hospital. Indian Journal of Pharmaceutical Sciences, 72(5), 587-591.

Kassiri, H., Haddad, M. H., Ghasemi, F., Rezaei, M., \& Ghanavati, F. (2012). An epidemiologic and demographic survey of poisoning in Southwest of Iran. MiddleEast Journal of Scientific Research, 12(7), 990-996. doi:10.5829/idosi. mejsr.2012.12.7.7155
Kielb, C., Lin, S., Muscatiello, N., Hord, W., Rogers-Harrington, J., \& Healy, J. (2015). Building-related health symptoms and classroom indoor air quality: A survey of school teachers in New York State. Indoor Air,25(4), 371-380.doi:10.1111/ ina. 12154

Lai, M. W., Klein-Schwartz, W., Rodgers, G. C., Abrams, J. Y., Haber A. B, D. A., Bronstein, A. C., \& Wruk R. N, K. M. (2006). 2005 Annual Report of the American Association of Poison Control Centers' National Poisoning and exposure database. Clinical Toxicology, 44(6-7), 803-932. doi: $10.1080 / 15563650600907165$

Lam, L. T. (2003). Childhood and adolescence poisoning in NSW, Australia: An analysis of age, sex, geographic, and poison types. Injury Prevention, 9(4), 338-342. doi:10.1136/ip.9.4.338

Launiala, A. (2009). How much can a KAP survey tell us about people's knowledge, attitudes and practices? Some observations from medical anthropology research on malaria in pregnancy in Malawi. Anthropology Matters, 11(1), 1-19.

Lekei, E., Ngowi, A. V., \& London, L. (2017). Acute pesticide poisoning in children: Hospital review in selected hospitals of Tanzania. Journal of Toxicology, 2017, 1-8.doi:10.1155/2017/4208405

Maciejewski, G. (2016). Purchasing places of consumer goods in selected European countries. Oeconomia, 15(2), 87-101.

Mahidin, M. U. (2017). Press release report of household income and basic amenities survey 2016 (pp. 1-7) (Malaysia, Department of Statistics Malaysia, Jabatan Perangkaan Malaysia). Kuala Lumpur: Public Relation Officer.

Manzar, N., Ali Saad, S. M., Manzar, B., \& Fatima, S. S. (2010). The study of etiological and demographic characteristics of acute household accidental poisoning in children--a consecutive case series study 
from Pakistan. BMC Pediatrics, 10, 28. doi:10.1186/1471-2431-10-28

Mansori, K., Soori, H., Farnaghi, F., Khodakarim, S., Mansouri Hanis, S., \& Khodadost, M. (2016). A Case-control study on risk factors for unintentional childhood poisoning. Medical Journal of the Islamic Republic of Iran (MJIRI), 30(1), 355-362. Retrieved August 1, 2019.

Marks, C. J., \& Hoving, D. J. (2016). A 3-year survey of acute poisoning exposures in infants reported in telephone calls made to the Tygerberg Poison Information Centre, South Africa. South Africa Journal Child Health, 10(1), 43-46. doi:10.7196/ SAJCH.2016.v10i1.1045

Mbeng, L., Probert, J., Phillips, P., \& Fairweather, R. (2009). Assessing public attitudes and behaviour to household waste management in Cameroon to drive strategy development: A Q Methodological Approach. Sustainability, 1(3), 556572. doi:10.3390/su1030556

McKenzie, L. B., Ahir, N., Stolz, U., \& Nelson, N. G. (2010). Household cleaning productrelated injuries treated in US Emergency Departments in 1990-2006. Pediatrics, 126(3), 509-516. doi:10.1542/peds.20093392

Meyer, S., Eddleston, M., Bailey, B., Desel, H., Gottschling, S., \& Gortner, L. (2007). Unintentional household poisoning in children. Klinische Padiatrie, 219(5), 254270. doi:10.1055/s-2007-972567

Moazzam, M., Al-Saigul, A. M., Naguib, M., \& Alfi, M. A. (2009). Pattern of acute poisoning in Al-Qassim region: A surveillance report from Saudi Arabia, 1999-2003. Eastern Mediterrian Health Journal, 15(4), 1005-1010.

Muleme, J., Kankya, C., Ssempebwa, J. C., Mazeri, S., \& Muwonge, A. (2017). A framework for integrating qualitative and quantitative data in knowledge, attitude, and practice studies: A case study of pesticide usage in Eastern Uganda. Frontiers in Public Health , 5(318), 1-15. doi:10.3389/ fpubh.2017.00318

National Safety Council. (n.d.). Poisons: What parents need to know. Retrieved June 10, 2019, from https://www.nsc.org/ home-safety/safety-topics/other-poisons/ household-products

Nixon, J. (2004). Community based programs to prevent poisoning in children $0-15$ years. Injury Prevention, 10(1), 43-46. doi:10.1136/ip.2003.003822

Peshin, S. S., \& Gupta, Y. (2018). Poisoning due to household products: A ten years retrospective analysis of telephone calls to the National Poisons Information Centre, All India Institute of Medical Sciences, New Delhi, India. Journal of Forensic and Legal Medicine, 58, 205-211. doi:10.1016/j. jflm.2018.07.005

Presgrave, R. D., Camacho, L. B., \& Villas Boas, M. S. (2008). A profile of unintentional poisoning caused by household cleaning products, disinfectants and pesticides. Cadernos De Saude Publica, 24(12), 2901-2908. doi:10.1590/S0102311X2008001200019

Rajapakse, T., Griffiths, K. M., Christensen, H., \& Cotton, S. (2014). A comparison of non-fatal self-poisoning among males and females, in Sri Lanka. BMC Psychiatry, 14(221), 1-13. doi: 10.1186/ s12888-014-0221-z

Rajasuriar, R., Awang, R., Hashim, S., \& Rahmat, H. (2007). Profile of poisoning admissions in Malaysia. Human \& Experimental Toxicology, 26, 73-81. doi:10.1177/0960327107071857

Rosenberg, M., Wood, L., Leeds, M., \& Wicks, S. (2011). "But they can't reach that high ...". Parental perceptions and knowledge relating to childhood poisoning. Health Promotion Journal of Australia, 22(3), 217223. doi:10.1071/HE11217 
Sackitey, G. L. (2018). Knowledge, attitude and perception on prevention of home accidents among mothers who came to the Pediatrics Department of the Korle-Bu Teaching Hospital. Journal of Health Education Research \& Development, 6(1), 1-10. doi:10.4172/2380-5439.1000242

Sena, B., Zaki, S. A., Yakub, F., Yusoff, N. M., \& Ridwan, M. K. (2018). Conceptual framework of modelling for Malaysian household electrical energy consumption using Artificial Neural Network based on Techno-Socio Economic Approach Boni. International Journal of Electrical and Computer Engineering (IJECE), 8(3), 1844-1853. doi:10.11591/ijece.v8i3. pp1844-1853

Sharif, L., \& Al-Malki, T. (2010). Knowledge, attitude and practice of Taif University students on food poisoning. Food Control, 21(1), 55-60.doi:10.1016/j. foodcont.2009.03.015

Tangiisuran, B., Jiva, M., Ariff, A. M., Abdul Rani, N., Misnan, A., Rashid, S. M., Dawson, A. H. (2018). Evaluation of types of poisoning exposure calls managed by the Malaysia National Poison Centre (20062015): A retrospective review. BMJ Open, 8, 1-7. doi:10.1136/bmjopen-2018-024162

Watson, W. A., Litovitz, T. L., Klein-Schwartz, W., Rodgers, G. C., Youniss, J., Reid, N., Borys, D. (2004). 2003 Annual Report of the American Association of Poison Control
Centers Toxic Exposure Surveillance

System. The American Journal of Emergency Medicine, 22(5), 335-404. doi: 10.1016/j.ajem.2004.06.001

Werner, P. D. (1977). Implications of attitudebehavior studies for population research and action. Studies in Family Planning, 8(11), 294. doi: $10.2307 / 1966280$

Wilkinson, A., Parker, M., Martineau, F., \& Leach, M. (2017). Engaging 'Communities': Anthropological insights from the West African Ebola Epidemic. Philosophical Transactions of the Royal Society B: Biological Sciences, 372(1721), 20160305. doi:10.1098/rstb.2016.0305

World Health Organization (WHO). (2005). World Health Statistics (pp. 1-59, Rep. No. Part 1). 20 Avenue Appia, Switzerland: WHO Press.

World Health Organization (WHO). (2010). Guidelines for poison control. Retrieved January 13, 2019, from https://www.who. int/ipcs/publications/training_poisons/ guidelines_poison_control/en/index $5 . \mathrm{html}$

World Health Organization (WHO). (2012). Poisoning Prevention and Management. Retrieved November 4, 2018, from https:// www.who.int/ipcs/poisons/en/

World Health Organization (WHO). (2019). Suicide. Retrieved November 18, 2019, from https://www.who.int/news-room/factsheets/detail/suicide. 